OPEN ACCESS

Edited by:

Chan Wang,

Guangdong University of Finance and Economics, China

Reviewed by:

Huihui Wang

Cleveland State University,

United States

Yongran Lin,

Henan Administration Institute, China

*Correspondence:

Zi-gui Chen

chenzigui0213@163.com

Specialty section:

This article was submitted to

Sustainable Energy Systems and Policies,

a section of the journal

Frontiers in Energy Research

Received: 20 February 2021

Accepted: 31 March 2021

Published: 21 April 2021

Citation:

Wu W-p, Zeng W-k, Gong S-w and Chen Z-g (2021) Does Energy Poverty Reduce Rural Labor Wages?

Evidence From China's Rural Household Survey.

Front. Energy Res. 9:670026. doi: 10.3389/fenrg.2021.670026

\section{Does Energy Poverty Reduce Rural Labor Wages? Evidence From China's Rural Household Survey}

\author{
Wei-ping Wu ${ }^{1,2}$, Wei-kang Zeng ${ }^{1}$, Si-wen Gong ${ }^{3}$ and Zi-gui Chen ${ }^{1,4 *}$ \\ ${ }^{1}$ Key Laboratory of Digital Economy and High Quality Development, Hunan University of Technology and Business, \\ Changsha, China, ${ }^{2}$ School of Economy and Trade, Hunan University, Changsha, China, ${ }^{3}$ School of Finance, Shanghai \\ University of Finance and Economics, Shanghai, China, ${ }^{4}$ Design and Art Institute, Hunan University of Technology \\ and Business, Changsha, China
}

Eliminating energy poverty is helpful to get rid of the vicious circle between the lack of adequate and affordable energy services and low income in rural areas. We deconstruct energy poverty into extensive energy poverty and intensive energy poverty and analyze the net effect and its heterogeneity of energy poverty on rural labor wages with micrometric methods, as well as further investigate the impact mechanism from education effect and health effect. The results show that both extensive energy poverty and intensive energy poverty have a significant negative effect on the wages of rural workers, and the marginal effect of extensive energy poverty on the wages of rural workers is lower than that of intensive energy poverty. In addition, the net effect of energy poverty on the wages of rural workers shows labor heterogeneity and regional heterogeneity, and the inhibition effect to low skilled workers and workers with middle wage and in the Western region is the most obvious. Furthermore, energy poverty will limit the access of rural workers to education and damage their health, and then inhibit their productivity and wage. Our results suggest that enhancing the accessibility of energy consumption in rural areas and reducing the incidence of energy poverty are critically essential, and the implementation and optimization of energy poverty alleviation policy should give full consideration to labor force heterogeneity and regional heterogeneity.

\section{Keywords: energy poverty, wages, labor heterogeneity, rural workers, education effect, health effect}

\section{INTRODUCTION}

Energy poverty is one of the three major challenges facing the energy system of the world and an important symbol of poverty in developing countries, which has been plagued by the development of some countries and regions (Che et al., 2021). On the one hand, the energy structure of rural households based on fossil energy and traditional biomass energy has not been broken. The extensive use of energy has caused certain environmental pollution and restricted the improvement of the quality of life of rural families (Gupta et al., 2020). According to the third agricultural census report of China in 2017, the proportion of electricity used in the surveyed households was $58.6 \%$; the proportion of gas, natural gas, and liquefied petroleum gas used was $49.3 \%$; the proportion of firewood used was $44.2 \%$; the proportion of coal used was $23.9 \%$; the proportion of biogas and 
solar energy used was $0.9 \%$; and the proportion of other energy used was $0.5 \%$. On the other hand, energy poverty has widened the life quality gap among residents of different income classes and become a "stumbling block" for low-income rural families to pursue a happy life. According to the National Bureau of Statistics of China, the per capita disposable income of rural households in 2019 was 16,020.7 yuan, which is only $37.8 \%$ of the per capita disposable income of urban residents. And the housing expenditure of rural households (including water, electricity, gas, and heating expenditure) was 2,871.3 yuan, which is only $42.3 \%$ of the housing expenditure of urban residents. Rural household energy supply is insufficient, and the utilization structure is unreasonable, which make it difficult to get rid of the low-income dilemma.

Eliminating energy poverty and promoting the balanced development between urban and rural areas have become the common goals in developing countries (Bardazzi et al., 2021; Faiella and Lavecchia, 2021). The Chinese government attaches great importance to the problem of rural families getting rid of energy poverty and increasing their income and has issued a series of policies, which have achieved certain results. In 2018, the National Energy Administration of China issued the notice of the action plan for further supporting energy development in poor areas and boosting poverty alleviation (2018-2020), which clearly put forward the strategic goal of "orderly and effective promotion of energy development in poor areas and significant improvement of energy universal service level." The data released by the National Energy Administration of China in 2020 show that in the past 8 years, the accumulated investment in major energy projects in poor areas has exceeded 2.7 trillion yuan, which has effectively driven the local economic development and played an important role in poverty alleviation. So, whether and how energy poverty reduces rural labor wages at the micro level has become the focus of this study. The main marginal contributions of this study are shown in two aspects. First, we deconstruct energy poverty into extensive energy poverty and intensive energy poverty and implement a more comprehensive measurement using the Foster-Greer-Thorbecke (FGT) index and the micro-survey data of the rural household of China. Second, we empirically study the net effect and its heterogeneity of energy poverty on rural labor wages with micrometric methods and further investigate the impact mechanism of energy poverty on rural labor wages from education effect and health effect, which provides a new explanation for energy poverty alleviation.

\section{LITERATURE REVIEW AND HYPOTHESIS}

Energy is the material basis for the survival and development of human society (Fabbri and Gaspari, 2021). Energy poverty will not only restrict economic development but also affect the physical and mental health and labor productivity. British scholar Bradshaw and Hutton (1983) is the first to pay attention to the problem of energy poverty. According to the International Energy Agency (IEA), 2010 the energy-poor group is defined as the group that cannot obtain electricity or other modern clean energy services, but mainly relies on traditional biomass energy or other solid fuels for cooking and heating. In the existing research, energy poverty is mainly manifested as extensive energy poverty and intensive energy poverty (Chang et al., 2020). Among them, extensive energy poverty refers to the incidence of energy poverty in a country or region, that is, the proportion of households whose energy consumption is lower than the energy poverty line. Intensive energy poverty refers to the relative gap between the energy consumption of energy-poor families and the energy poverty line. From the existing literature, most studies have verified the negative correlation between comprehensive energy poverty and the income of rural residents (Liu et al., 2020) and believe that the key to poverty alleviation in rural areas lies in the realization of electrification (Dijk, 2012). However, it is rare to explore the impact of energy poverty on rural labor wage from the perspective of extensive energy poverty and intensive energy poverty. Specifically, the extensive energy poverty reflects the loss of modern energy resources and services to a large extent, which can not only create more employment opportunities (Dinkelman, 2011) but also improve labor productivity by driving modern tools (Ifeoluwa and Richard, 2021). Therefore, we infer that extensive energy poverty will have a negative impact on the wages of rural workers. In addition, intensive energy poverty reflects the difficulty of energy-poor families in obtaining modern energy resources and services (Apergis, 2015). Therefore, there is a negative correlation between intensive energy poverty and the wages of rural workers. At last, although the positive effects of electricity and clean energy use on the employment opportunities of women and labor productivity have reached consensus in academic circles, there are still differences in the effects of the use of electricity and clean energy on the productivity and wages of male workers (Grogan and Sadand, 2013; Topcu and Tugcu, 2019). This means that energy poverty will have a differential impact on the wages of different workers. Therefore, this article proposes proposition 1.

Proposition 1. Energy poverty will have a negative effect on the wages of rural workers from both extensive and intensive energy poverty, and this effect will be different for different workers.

So, how can energy poverty restrain the wages of rural workers? What researchers have discussed is that energy poverty limits the educational attainment and health of individual workers. And the positive correlation between education and health level and individual labor productivity has been supported by existing studies (Lucas, 1988, 2004). From the perspective of education, family energy poverty will lead school-age children to spend more time on collecting firewood and other resources, and the access to education will be limited (Sothea, 2019). Moreover, this inhibitory effect is more obvious for rural female children, because they need to spend more time on household energy collection (Nankhuni and Findeis, 2004; Ndiritu and Nyangena, 2011). In addition, the research of Martins (2005); Khandker et al. (2012), and Aguirre (2014) show that the promotion of electrification has a positive effect on the enrollment rate and home study time of school-age children and significantly improves the average education level in this region. From the 
perspective of health, energy poverty will damage the health of residents and then limit their productivity and wages (Gordon et al., 2014; Sadath and Acharya, 2017; Zhang et al., 2019). For example, Barreca et al. (2014) found that reducing the use of coal in heating resulted in a decrease of about $1.25 \%$ in the mortality rate of the whole age population and $3.27 \%$ in the infant mortality rate in the United States between 1945 and 1960. Based on Turkish data, Cesur et al. (2018) found that replacing coal with natural gas significantly reduced the risk of death for adults and the elderly, and every $1 \%$ increase in household natural gas ordering rate resulted in a decrease of about $1.4 \%$ in the overall mortality rate for adults and the elderly. Maji et al. (2021) found that electrification can reduce the probability of cough by about 35-50\%. In short, energy poverty not only limits the possibility of rural workers obtaining education resources but also damages their health, resulting in the loss of human capital and labor productivity. Therefore, this article proposes the second and third theoretical hypotheses:

Proposition 2. Energy poverty will limit the access of rural workers to education during school age, resulting in loss of human capital and labor productivity.

Proposition 3. Energy poverty will damage the health of rural workers, resulting in the damage of labor productivity and wages.

\section{MATERIALS AND METHODS}

\section{Data}

The data used in this article are derived from the Chinese General Social Survey (CGSS) in 2015, which includes six modules, such as "Core Module," "Ten Years Review," "EASS Module," "ISSP Module," "Energy Module," and "Legal Module," The contents of the survey involve the basic personal information of the subjects, family information, social attitudes, energy use, and knowledge of laws and regulations. The reason why we choose CGSS 2015 as research data is based on two considerations: first, the "Energy Module" only exists in CGSS 2015, and the data can meet the demand of this article for the index data of extensive energy poverty and intensive energy poverty measurement. Second, CGSS is the earliest national, comprehensive, and continuous academic investigation project in China, which adopted multiorder stratified probability proportionate to size (PPS) random sampling method and covered more than 10,000 households in 25 provinces across the country.

Due to the inseparable relationship between the energy access capacity and the overall resource endowment of households (Pachaul et al., 2004), we calculated the comprehensive energy consumption in households and then obtained the countylevel rural household energy poverty index by calculating the arithmetic mean. However, in CGSS, the units of fuel consumption such as electric power, pipeline natural gas, bottled liquefied gas, diesel, firewood, charcoal, and coal are different. So, we first converted them into kgce and then calculated the comprehensive energy consumption.

\section{Identification of Energy Poverty}

At present, the FGT index constructed by Foster and Thorbecke (1984) is widely used to measure energy poverty in academic circles. Since this study focuses on the extensive energy poverty and intensive energy poverty, we expand the FGT index to identify two different types of energy poverty index. The formula is as follows:

$$
P_{a}=\frac{1}{n} \sum_{i=1}^{q}\left(\frac{z-x_{i}}{z}\right)^{a}
$$

In this formula, $n$ is the total number of rural households in the sample area; $q$ is the number of rural households whose energy consumption is lower than the energy poverty line; zrepresents the energy poverty line; and $x_{i}$ is the energy consumption of household. In addition, we set the value of parameter $a$ to 0 or 1 . When $a$ is equal to $0, P_{0}$ represents the incidence of energy poverty, which is used to measure the extensive energy poverty index. When $a$ is equal to $1, P_{1}$ reflects the relative distance between the energy consumption of energy-poor households and the energy poverty line, which is used to measure the intensive energy poverty index.

As for the calculation of the energy poverty line, we first calculated the rural household energy consumption based on the rural per capita energy consumption and household population. According to China Statistical Yearbook 2016, the average number of people in each household in 2015 is 3.1. Combined with the 514.04 kgce per capita domestic energy consumption of Chinese rural households calculated by Qiu et al. (2015), we further calculated that the average domestic energy consumption of rural households in China is $1,593.52 \mathrm{kgce}$. Then, referring to the practice of Chang et al. (2020), the energy poverty line of rural households in China is 414 kgce by multiplying the average domestic energy consumption of rural households by the proportion coefficient of the national poverty line and the per capita net income of rural households.

\section{Model Specification}

Theoretical studies show that the impact path of extensive energy poverty and intensive energy poverty on the wages of rural workers is different, which means that there will be a gap between the two effects on rural labor wages. In order to identify this different effect, this article constructs a wage decision model at the individual level to test the net effect of extensive energy poverty and intensive energy poverty on the wages of rural workers, as follows:

$$
\begin{aligned}
& \ln \left(\text { wage }_{i j t}\right)=\alpha+\beta_{1} \text { ex_poverty } y_{j t}+\gamma_{1} \text { ind_control }{ }_{i j t} \\
& +\gamma_{2} \text { fam_control }_{j t}+\varepsilon_{i j t} \\
& \ln \left(\text { wage }_{i j t}\right)=\alpha+\beta_{2} \text { in_poverty }_{j t}+\gamma_{1} \text { ind_control } l_{i j t} \\
& +\gamma_{2} \text { fam_control }_{j t}+\varepsilon_{i j t}
\end{aligned}
$$

In Equations 2, 3, $i$ represents the rural individuals, $j$ represents the county, $t$ is the time, $\ln ($ wage $)$ is the natural logarithm of the wages of rural workers, and ex_poverty and in_poverty represent the extensive energy poverty and 
the intensive energy poverty, respectively. ind_control and fam_control are used to control the individual attribute factors and family factors affecting the wages of rural workers, respectively. The coefficient $\beta$ represents the net effect of energy poverty on the wages of rural workers, and $\gamma$ represents the estimated coefficient of each control variable. $\varepsilon$ is a random disturbance term.

The individual attributes and family factors controlled in this article are gender, age, marriage, education, experience, total household income ( $h \_$income), and number of household real estate (real_estate). Specifically, for measures of gender, the female is assigned 0 and the male is assigned 1. For marital status, the value of unmarried is 0 , and the value of first marriage, remarriage, divorce, and widowed is 1 . For education level, the value of not having attended school is 1 , the value of primary school (including literacy class) is 2, the value of junior high school is 3 , the value of senior high school (including technical secondary school) is 4 , the value of junior college is 5 , the value of undergraduate college is 6 , and the value of graduate school is 7. As for work experience, it is obtained by the time that the interviewees have been engaged in their first non-agricultural work so far. In addition, we also control the age squared term according to the general practice of existing literature (Wu et al., 2020).

\section{RESULTS}

\section{Baseline Regression}

Table 1 represents the baseline estimates for models (2) and (3). The net effect of extensive energy poverty on rural labor wages is reported in columns $1-3$, and the net effect of intensive energy poverty on rural labor wages is reported in columns 46 . We gradually increased the control variables in the estimation equations, so as to reduce the multicollinearity problem and enhance the robustness of the estimation results. Among them, columns 1 and 4 do not include control variables; columns 2 and 5 include individual attribute factors; and columns 3 and 6 include both individual attribute factors and family factors. The results show that both extensive energy poverty and intensive energy poverty have a significant negative effect on the wages of rural workers, no matter whether the control variable is added or not. Specifically, the marginal effect of extensive energy poverty on the wages of rural workers is -0.21 , which is lower than that of the intensive energy poverty by -0.36 . It shows that even though the incidence of energy poverty will reduce the wages of rural workers, the inhibitory effect on the wages of rural workers is less than that of the intensive energy poverty. Therefore, to expand the effect of energy on economic poverty alleviation, in addition to enhancing the accessibility of energy consumption in rural areas and reducing the incidence of energy poverty, narrowing the gap between the energy consumption of rural low-income families and the energy poverty line is even more important.

From the estimation results of control variables, the estimation coefficient of gender is significantly positive, and the marginal coefficient is 0.30 , indicating that the average wage of rural male workers is $30 \%$ higher than that of female workers. This is because in Chinese tradition, in addition to more domestic activities, rural women also take care of the elderly and children, which affects their labor supply and productivity. The estimation coefficient of age is significantly positive and that of the age square term is significantly negative, which indicates that there is an inverted U-shaped relationship between the wages and age of the rural workers, and the inflection point is about 38 years old. The estimated coefficient of marriage variable is significantly positive and 0.14 , which means that the average wage of married rural workers is $14 \%$ higher than that of unmarried individuals. Education and work experience are positively correlated with the wages of rural workers, and the marginal coefficients are 0.08 and 0.005 , respectively. In addition, the total household income also has a positive effect on the wages of rural individual workers, and every $1 \%$ increase in the total household income will lead to an increase of $0.69 \%$ in the average wages of individual workers. However, there is a significant negative correlation between the number of household real estate and the wages of rural workers, and each increase in household real estate will reduce the wages of rural workers by $1.42 \%$. This is because the increase in the number of household real estate will reduce the employment participation and labor time supply of individual workers and then pull down their wages.

\section{Heterogeneity Analysis Quantile Regression Estimation}

According to the statistical data, there are differences in the employment industry and occupation distribution of rural workers with different wage levels, which means that rural workers with different wage levels may be affected differently by energy poverty. In order to verify this inference, we use the Quantile regression model (QR) to further investigate the differentiated effect of energy poverty on the wages of rural workers at different quantiles. Table 2 reports the response of the wages of rural workers to the extensive energy poverty and intensive energy poverty at the 25th, 50th, and 75th quantile. Among them, no matter in the estimation equation of extensive energy poverty or intensive energy poverty, energy poverty has a significant inhibitory effect on the wages of rural workers at all quantiles. Furthermore, compared with the rural workers with higher and lower wage income, the middle wage group is more negatively affected by the extensive energy poverty and intensive energy poverty. In summary, proposition 1 has been proved.

\section{Labor Force Heterogeneity}

In reality, rural workers are not homogeneous individuals, but have obvious heterogeneity of human capital. The differences in human capital will not only lead to the emergence of labor stratification but also promote different types of workers to show different identities and labor productivity in the labor market. Therefore, this part will focus on the net effect of energy poverty on the wages of rural workers with different skills. By reference to Borjas (1999), we divide the rural workers into two types: high-skilled workers and low-skilled workers according to their education or work experience. Among them, the workers with university degree or above are divided into high-skilled workers, and the workers with high school degrees or below are 
TABLE 1 | Baseline regression estimation results.

\begin{tabular}{|c|c|c|c|c|c|c|}
\hline & \multicolumn{6}{|c|}{ Dependent variable: $\ln ($ wage) } \\
\hline & (1) & (2) & (3) & (4) & (5) & (6) \\
\hline In_poverty & & & & $-0.4684^{\star \star \star}(0.1608)$ & $-0.4574^{\star \star \star}(0.1565)$ & $-0.3670^{\star \star \star}(0.1162)$ \\
\hline Gender & & $0.2798^{\star \star \star}(0.0276)$ & $0.2971^{\star \star \star}(0.0206)$ & & $0.2809^{\star \star \star}(0.0276)$ & $0.2976^{\star \star \star}(0.0206)$ \\
\hline Age & & $0.0352^{\star \star \star}(0.0081)$ & $0.0283^{\star \star \star}(0.0061)$ & & $0.0352^{\star \star \star}(0.0081)$ & $0.0283^{\star \star \star}(0.0062)$ \\
\hline Marriage & & $0.1025^{\star \star}(0.0467)$ & $0.1369^{\star \star}(0.0534)$ & & $0.1046^{\star \star}(0.0467)$ & $0.1379^{\star \star \star}(0.0354)$ \\
\hline Education & & $0.2653^{\star \star \star}(0.0104)$ & $0.0826^{\star \star \star}(0.0084)$ & & $0.2645^{\star \star \star}(0.0104)$ & $0.0822^{\star \star \star}(0.0084)$ \\
\hline Experience & & $0.0163^{\star \star \star}(0.0017)$ & $0.0055^{\star \star \star}(0.0013)$ & & $0.0163^{\star \star \star}(0.0017)$ & $0.0051^{\star \star \star}(0.0013)$ \\
\hline Ln(h_income) & & & $0.6885^{\star \star \star}(0.0126)$ & & & $0.6880^{\star \star \star}(0.0125)$ \\
\hline Real_estate & & & $-0.0142^{\star \star \star}(0.0053)$ & & & $-0.0141^{\star \star \star}(0.0053)$ \\
\hline F Stats. & $13.550^{\star \star \star}$ & $169.100^{\star \star \star}$ & $567.070^{\star \star \star}$ & $18.480^{\star \star \star}$ & $169.910^{\star \star \star}$ & $567.640^{\star \star \star}$ \\
\hline
\end{tabular}

${ }^{* * *} P<0.01$ and ${ }^{* *} P<0.05$, robust standard errors in parentheses.

TABLE 2 | Quantile regression estimation results.

Dependent variable: $\ln ($ wage $)$

\begin{tabular}{|c|c|c|c|c|c|}
\hline \multicolumn{2}{|c|}{25 points } & \multicolumn{2}{|c|}{50 points } & \multicolumn{2}{|c|}{75 points } \\
\hline (1) & (2) & (3) & (4) & (5) & (6) \\
\hline$-0.1839^{\star}(0.1033)$ & & $-0.3947^{\star \star \star}(0.1207)$ & & $-0.2119^{\star \star \star}(0.1231)$ & \\
\hline & $-0.2072^{\star \star}(0.1026)$ & & $-0.4260^{\star \star \star}(0.0033)$ & & $-0.2378^{\star \star}(0.1143)$ \\
\hline Yes & Yes & Yes & Yes & Yes & Yes \\
\hline Yes & Yes & Yes & Yes & Yes & Yes \\
\hline 0.3981 & 0.3982 & 0.4164 & 0.4167 & 0.4395 & 0.4397 \\
\hline 3,364 & 3,364 & 3,364 & 3,364 & 3,364 & 3,364 \\
\hline
\end{tabular}

${ }^{* * *} P<0.01,{ }^{* *} P<0.05$, and ${ }^{*} P<0.1$, robust standard errors in parentheses.

divided into low-skilled workers. In addition, workers above the average value of work experience are classified as high-skilled workers, and workers below the average value are classified as low-skilled workers.

Table 3 reports the net effects of extensive energy poverty and intensive energy poverty on the wages of rural workers with different skills. The results show that whether grouped by education or work experience, extensive energy poverty and intensive energy poverty have a significant inhibitory effect on the wages of rural workers with different skills. Comparatively speaking, the wage of low-skilled workers is more restrained by two types of energy poverty. In addition, whether in the sample of low-skilled workers or high-skilled workers, the results of labor heterogeneity analysis further verify that the inhibitory effect of extensive energy poverty on the wages of rural workers is greater than that of intensive energy poverty. These findings further support proposition 1 .

\section{Region Heterogeneity}

Due to the large gap in economic development and the obvious difference of energy resource endowment in Eastern, Central, and Western China, there will be differences in the energy resource supply and labor employment policies. Based on the above considerations, we also examined the net effect of extensive energy poverty and intensive energy poverty on the wages of rural workers in different regions (Table 3 ). The results show that extensive energy poverty and intensive energy poverty only have significant negative effects on the wages of rural workers in the central and western regions, but not in the eastern region. Specifically, the estimated coefficients of extensive energy poverty in central and western regions are -0.15 and -0.41 , and the estimated coefficients of intensive energy poverty in central and western regions are -0.29 and -0.40 , respectively. This means that the restraining effect of extensive energy poverty and intensive energy poverty on the wages of rural workers is more prominent in the western regions. Therefore, the implementation and optimization of energy poverty alleviation policy should also give full consideration to regional heterogeneity.

\section{Mechanism Analysis Education Effect}

Theoretical research shows that the negative impact of energy poverty on the academic education and non-academic education of rural workers will further affect their labor productivity and 
wages, which will be more prominent for rural female workers. Due to the heavy labor cost of solid fuel collection, female workers have to reduce their opportunities to participate in education and training, employment, and other productive activities with income (Cooke, 1998). In developing countries, female workers spend seven times as much time collecting fuel as adult male workers and 3.5 times as much time as male workers of the same age. This is no exception in China. A survey on the time distribution of "indoor" activities of farmers in poor areas of China shows that female workers spend an average of $26 \mathrm{~h}$ a week collecting firewood and cooking activities, which is much higher than that of male workers who spend $9 \mathrm{~h}$ a week (Ding and Chen, 2002).

In order to verify the negative effect of energy poverty on the education of rural workers, we empirically test the education effect of energy poverty on rural workers with mediation effect model. In the benchmark regression equation, we have verified a significant positive correlation between education and the wages of workers. Therefore, according to the identification logic of mediating effect model, we can confirm that energy poverty will affect the wages of rural workers through the education effect as long as we verify that there is a significant negative effect of energy poverty on the education of rural workers. In Table 4, columns 1 and 2, respectively, report the net impact of extensive energy poverty and intensive energy poverty on the education of rural workers. It can be seen that both extensive energy poverty and intensive energy poverty reduce the average education level of rural workers, and the marginal coefficients are -0.56 and -0.24 , respectively, which is in line with the above proposition 2 . In addition, from the estimation results of female and male subsamples, the two types of energy poverty significantly reduce the average education level of female and male individuals. Comparatively speaking, the average education level of female workers is more restrained by energy poverty.

\section{Health Effect}

Theoretical research infers that energy poverty will damage the health of rural workers and then inhibit their labor productivity and wage. In fact, the extensive use of solid fuels such as firewood and coal will damage the health of residents, which has been fully verified in western countries. For example, Peabody et al. (2005) evaluated the health effects of various types of cooking fuels from the aspects of exhaled carbon monoxide content, maximum vital capacity, and the prevalence of chronic obstructive pulmonary disease and found that solid fuels were the most harmful source to health. Lim et al. (2012) evaluated the risk factors of diseases and

TABLE 3 | Heterogeneity analysis.

Dependent variable: In(wage)

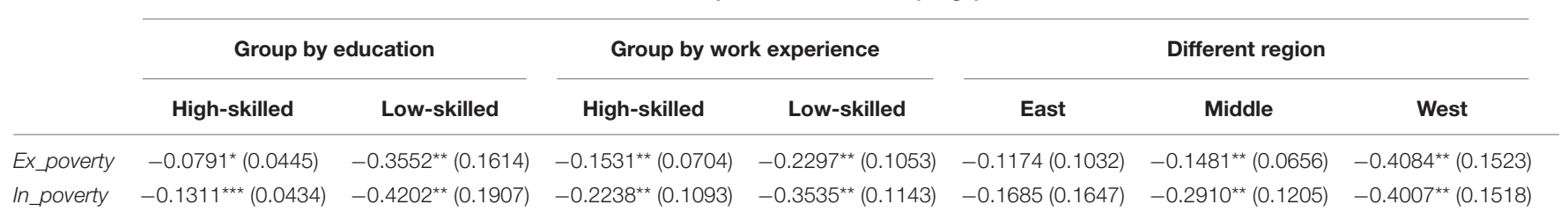

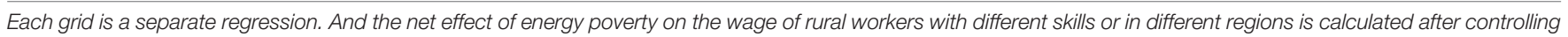
individual attributes, family factors that affect the wage of rural workers. ${ }^{* *} P<0.01,{ }^{* *} P<0.05$, and ${ }^{*} P<0.1$, robust standard errors in parentheses.

TABLE 4 | Education effect analysis.

\begin{tabular}{|c|c|c|c|c|c|c|}
\hline & \multicolumn{6}{|c|}{ Dependent variable: education } \\
\hline & \multicolumn{2}{|c|}{ All samples } & \multicolumn{2}{|c|}{ Male workers } & \multicolumn{2}{|c|}{ Female workers } \\
\hline & (1) & (2) & (3) & (4) & (5) & (6) \\
\hline Ex_poverty & $-0.5603^{\star \star \star}(0.1674)$ & & $-0.5407^{\star \star}(0.2316)$ & & $-0.5863^{\star \star}(0.2361)$ & \\
\hline In_poverty & & $-0.2434^{\star \star}(0.1056)$ & & $-0.1884^{\star}(0.1202)$ & & $-0.2833^{\star *}(0.1333)$ \\
\hline
\end{tabular}

TABLE 5 | Health effect analysis.

Dependent variable: health

\begin{tabular}{|c|c|c|c|c|c|}
\hline \multicolumn{2}{|c|}{ All samples } & \multicolumn{2}{|c|}{ Male workers } & \multicolumn{2}{|c|}{ Female workers } \\
\hline (1) & (2) & (3) & (4) & (5) & (6) \\
\hline$-0.6129^{\star \star \star}(0.1230)$ & & $-0.4608^{\star \star \star}(0.1715)$ & & $-0.7893^{\star \star \star}(0.1753)$ & \\
\hline & $-0.3512^{\star \star \star}(0.1217)$ & & $-0.1403^{\star \star}(0.0695)$ & & $-0.5952^{\star \star \star}(0.1736)$ \\
\hline
\end{tabular}


injuries and found that indoor air pollution caused by solid fuel utilization caused 3.55 million premature deaths worldwide in 2010. So, does the health damage effect from energy poverty exist in China? Similar to the education effect test, we tested the health effect of energy poverty on rural workers with the mediating effect model. In the benchmark regression equation, we have verified the significant positive correlation between health and the wages of workers. Therefore, as long as we verify that energy poverty has a significant negative effect on the health of rural workers, we can confirm that energy poverty will affect the wages of rural workers through the health effect. According to the estimated results in Table 5, both extensive energy poverty and intensive energy poverty significantly reduce the health level of rural workers, and this health damage effect is more obvious for female workers, that is, proposition 3 has been proved.

\section{CONCLUSION AND POLICY IMPLICATIONS}

This study deconstructed energy poverty into extensive energy poverty and intensive energy poverty and analyzed the net effect and its heterogeneity of energy poverty on rural labor wages with micrometric methods; it further investigated the impact mechanism of energy poverty on rural labor wages from education effect and health effect. The following main conclusions were reached: first, both extensive energy poverty and intensive energy poverty have a significant negative effect on the wages of rural workers, and the marginal effect of extensive energy poverty on the wages of rural workers is -0.21 , which is lower than that of intensive energy poverty by -0.36 . Second, the rural workers with middle wages are more negatively affected by the extensive energy poverty and intensive energy poverty. Third, extensive energy poverty and intensive energy poverty have a significant inhibitory effect on the wages of rural workers with different skills, and the wage of low-skilled workers is more restrained by two types of energy poverty. Fourth, the negative effect of extensive energy poverty and intensive energy poverty on the wages of rural workers is more prominent in the western regions. Fifth, energy poverty will limit the access of rural workers to education and damage their health, resulting in the decrease of labor productivity and wages.

There is often a vicious circle between the lack of adequate and affordable energy services and low income. As an important part of the millennium development goals of China and even the developing countries, eliminating energy poverty is helpful

\section{REFERENCES}

Aguirre, J. (2014). Impact of rural electrification on education: a case study from Peru. Lahore J. Econ. 22, 91-108. doi: 10.35536/lje.2017.v22.i1.a5

Apergis, N. (2015). Does renewables production affect income inequality? evidence from an international panel of countries. Appl. Econ. Lett. 22, 865-868. doi: 10.1080/13504851.2014.982852

Bardazzi, R., Bortolotti, L., and Pazienza, M. G. (2021). To eat and not to heat? energy poverty and income inequality in Italian regions. Energy Res. Soc. Sci. 73:101946. doi: $10.1016 /$ j.erss.2021.101946 to optimize the energy consumption structure in rural areas and get rid of the vicious circle of energy poverty. To expand energy poverty alleviation and its positive spillover effects on economic poverty alleviation, in addition to enhancing the accessibility of energy consumption in rural areas and reducing the incidence of energy poverty, narrowing the gap between energy consumption of rural low-income families and energy poverty line is even more important. Furthermore, the implementation and optimization of energy poverty alleviation policy should give full consideration to labor force heterogeneity and regional heterogeneity, avoiding one-size-fits-all policy formulation and implementation.

\section{DATA AVAILABILITY STATEMENT}

The original contributions presented in the study are included in the article/supplementary material, further inquiries can be directed to the corresponding author/s.

\section{AUTHOR CONTRIBUTIONS}

W-PW: conceptualization, writing - original draft, and methodology. W-KZ: data curation, software, and writing review editing. S-WG: methodology and writing - review editing. Z-GC: data curation and supervision. All authors contributed to the article and approved the submitted version.

\section{FUNDING}

This research is supported by the National Natural Science Foundation of China (Grant Nos. 71903056 and 71774053), National Science Foundation for Post-doctoral Scientists of China (Grant No. 2020M672464), MOE (Ministry of Education in China) Project of Humanities and Social Sciences (Grant No. 19YJC790154), Consulting Project of Chinese Academy of Engineering (Grant Nos. 2020-XY-36 and 2020-XZ-053), Natural Science Foundation of Hunan Province in China (Grant Nos. 2020JJ5104 and 2020JJ4259), Philosophy and Social Science Foundation of Hunan Province in China (Grant No. 18YBQ075), Project of Hunan Social Science Achievement Appraisal Committee (Grant Nos. XSP20YBZ081 and XSP21YBZ094), Scientific Research Project of Hunan Education Department in China (Project No. 19C1038), and Research and Innovation Project for Graduate Students in Hunan Province (Grant Nos. CX20201083 and CX20201084). 
Chang, H. Y., He, K., and Zhang, J. B. (2020). Energy poverty in rural China: a psychological explanations base on households. China Population Resour. Environ. 30, 11-20.

Che, X., Zhu, B., and Wang, P. (2021). Assessing global energy poverty: an integrated approach. Energy Policy 2021:112099. doi: 10.1016/j.enpol.2020. 112099

Cooke, P. A. (1998). The effect of environmental good scarcity on own-farm labor allocation: the case of agricultural households in rural Nepal. Environ. Dev. Econ. 3, 443-469. doi: 10.1017/s1355770x98000230

Dijk, K. V. (2012). The role of energy in creating opportunities for income generation in the Indian Himalayas. Energy Policy 41, 529-536. doi: 10.1016/j. enpol.2011.11.013

Ding, S. J., and Chen, C. B. (2002). Energy use by poor farmers and its impact on poverty alleviation. Chin. Rural Econ. 12, 27-32.

Dinkelman, T. (2011). The effects of rural electrification on employment: new evidence from South Africa. Am. Econ. Rev. 101, 3078-3108. doi: 10.1257/aer. 101.7.3078

Fabbri, K., and Gaspari, J. (2021). Mapping the energy poverty: a case study based on the energy performance certificates in the city of Bologna. Energy Build. 234:110718. doi: 10.1016/j.enbuild.2021.110718

Faiella, I., and Lavecchia, L. (2021). Energy poverty. how can you fight it, if you can't measure it? Energy Build. 233:110692. doi: 10.1016/j.enbuild.2020.110692

Foster, J., and Thorbecke, G. E. (1984). A class of decomposable poverty measures. Econometrica 52, 761-766. doi: 10.2307/1913475

Gordon, S. B., Bruce, N. G., Grigg, J., Hibberd, P. L., Kurmi, O. P., Lam, K. B., et al. (2014). Respiratory risks from household air pollution in low and middle income countries. Lancet Respir. Med. 2, 823-860.

Grogan, L., and Sadand, A. (2013). Rural electrification and employment in poor countries: evidence from Nicaragua. World Dev. 43, 252-265. doi: 10.1016/j. worlddev.2012.09.002

Gupta, S., Gupta, E., and Sarangi, G. K. (2020). Household energy poverty index for India: an analysis of inter-state differences. Energy Policy 144:111592. doi: 10.1016/j.enpol.2020.111592

Ifeoluwa, G., and Richard, B. (2021). Energy poverty: estimating the impact of solid cooking fuels on GDP per capita in developing countries case of sub-Saharan Africa. Energy 7:119770. doi: 10.1016/j.energy.2021. 119770

International Energy Agency (IEA) (2010). Energy Poverty: How to Make Modern Energy Access Universal? World Energy Outlook. Paris: IEA.

Khandker, S. R., Samad, H. A., Ali, R., and Barnes, D. F. (2012). Who benefits most from rural electrification? evidence in India. Energy J. 35, 75-96.

Lim, S., Vos, T., and Bruce, N. (2012). The burden of disease and injury attributable to 67 risk factors and risk factor clusters in 21 regions 1990-2010: a systematic analysis. Lancet 380, 2224-2260.

Liu, Z. M., Deng, M. Y., and Cui, Z. W. (2020). The impact of energy poverty on residents' welfare and its mechanism: an analysis based on CGSS data. China Soft Sci. 8, 143-163.

Lucas, R. (1988). On the mechanics of economic development. J. Monet. Econ. 22, 3-42. doi: 10.4135/9781452204550.n1

Lucas, R. E. (2004). Life earnings and rural-urban migration. J. Polit. Econ. 112, 29-59.
Maji, P., Mehrabi, Z., and Kandlikar, M. (2021). Incomplete transitions to clean household energy reinforce gender inequality by lowering women's respiratory health and household labour productivity. World Dev. 139:105309. doi: 10. 1016/j.worlddev.2020.105309

Martins, J. (2005). The impact of the use of energy sources on the quality of life of poor communities. Soc. Indic. Res. 72, 373-402. doi: 10.1007/s11205-0045583-Z

Nankhuni, F. J., and Findeis, J. L. (2004). Natural resource-collection work and children's schooling in Malawi. Agrc. Econ. 31, 123-134. doi: 10.1016/j.agecon. 2004.09.022

Ndiritu, S., and Nyangena, W. (2011). Environmental goods collection and children's schooling: evidence from Kenya. Reg. Environ. Change 11, 531-542. doi: 10.1007/s10113-010-0168-7

Pachaul, S., Mueller, A., Kemmier, A., and Spreng, D. (2004). On measuring energy poverty in Indian households. World Dev. 32, 2083-2104. doi: 10.1016/ j.worlddev.2004.08.005

Peabody, J. W., Riddell, T. J., Smith, K. R., Liu, Y., and Sinton, J. E. (2005). Indoor air pollution in rural china: cooking fuels, stoves, and health status. Arch. Environ. Occup. Health 60, 86-95. doi: 10.3200/aeoh.60.2.86-95

Qiu, H. G., Yan, J. B., and Li, D. W. (2015). Analysis of the current status of energy consumption, development trends and determinants of China's rural energy consumption: empirical research based on two-phase investigation in four province. China Soft Sci. 11, 28-38.

Sadath, A. C., and Acharya, R. H. (2017). Assessing the extent and intensity of energy poverty using multidimensional energy poverty index: empirical evidence from households in India. Energy Policy 102, 540-550. doi: 10.1016/j. enpol.2016.12.056

Sothea, O. (2019). Energy poverty in the Lao PDR and its impacts on education and health. Energy Policy 132, 247-253. doi: 10.1016/j.enpol.2019.05.030

Topcu, M., and Tugcu, C. T. (2019). The impact of renewable energy consumption on income inequality: evidence from developed countries. Renew. Energy 151, 1134-1140. doi: 10.1016/j.renene.2019.11.103

Wu, W. P., Cheng, Z. G., and Yang, D. X. (2020). Do internal migrants crowd out employment opportunities for urban locals in China?-reexamining under the skill stratification. Physica A 537, 1-16. doi: 10.1017/cbo9780511499401.002

Zhang, D., Li, J., and Han, P. (2019). A multidimensional measure of energy poverty in China and its impacts on health: an empirical study based on the China family panel studies. Energy Policy 131, 72-81. doi: 10.1016/j.enpol.2019. 04.037

Conflict of Interest: The authors declare that the research was conducted in the absence of any commercial or financial relationships that could be construed as a potential conflict of interest.

Copyright (c) $2021 \mathrm{Wu}$, Zeng, Gong and Chen. This is an open-access article distributed under the terms of the Creative Commons Attribution License (CC BY). The use, distribution or reproduction in other forums is permitted, provided the original author(s) and the copyright owner(s) are credited and that the original publication in this journal is cited, in accordance with accepted academic practice. No use, distribution or reproduction is permitted which does not comply with these terms. 